\title{
BMJ Open Detecting young people with mental disorders: a cluster-randomised trial of multidisciplinary health teams at the GP office
}

\author{
Ole Rikard Haavet (D) , ${ }^{1}$ Jūrate Šaltyte Benth, ${ }^{2,3}$ Svein Gjelstad, ${ }^{1}$ \\ Ketil Hanssen-Bauer, ${ }^{3,4}$ Mina Piiksi Dahli, ${ }^{1}$ Nick Kates, ${ }^{5}$ Torleif Ruud ${ }^{3,4}$
}

To cite: Haavet $O R$, Šaltytė Benth J, Gjelstad S, et al. Detecting young people with mental disorders: a cluster-randomised trial of multidisciplinary health teams at the GP office. BMJ Open 2021;11:e050036. doi:10.1136/ bmjopen-2021-050036

- Prepublication history for this paper is available online. To view these files, please visit the journal online (http://dx.doi. org/10.1136/bmjopen-2021 050036).

Received 08 February 2021 Accepted 01 December 2021

Check for updates

(c) Author(s) (or their employer(s)) 2021. Re-use permitted under CC BY-NC. No commercial re-use. See rights and permissions. Published by BMJ.

${ }^{1}$ Department of General Practice, Institute of Health and Society, University of 0slo, Oslo, Norway ${ }^{2}$ Health Services Research Unit, Akershus University Hospital, Lorenskog, Norway

${ }^{3}$ Division of Health Services Research and Psychiatry, Institute of Clinical Medicine, University of Oslo, Oslo, Norway ${ }^{4}$ Division of Mental Health Services, Akershus University Hospital, Lorenskog, Norway ${ }^{5}$ Department of Psychiatry \& Behavioural Neurosciences,

Michael G. DeGroote School of Medicine McMaster University, Hamilton, Ontario, Canada

Correspondence to

Professor Ole Rikard Haavet; o.r.haavet@medisin.uio.no

\section{ABSTRACT}

Background Young people with mental health challenges present a major global challenge. More than half of adults with mental disorders experience their onset before age 14 , but early detection and intervention may change this course. Shared care with mental health professionals in general practitioner (GP) offices has demonstrated its potential for improvement in these conditions.

Aim To investigate whether shared care with mental health professionals in GP offices increases the detection of youth's mental health disorders and is associated with a decrease in use of unspecified symptom diagnoses, as a whole and stratified by patient and physician gender and age, and type of consulting physician.

Design and setting This was a stratified clusterrandomised controlled trial with data extraction from electronic records. Two GP offices were recruited from each of three boroughs. Each borough had 3-8 GP offices. One GP office was randomised to the intervention group and the other to the control group.

Method We used generalised linear mixed models to assess whether the intervention helped GPs identify more International Classification of Primary Care 2 diagnoses of depression, anxiety and unspecified symptoms in youth.

Results Over a 18-month period between between 2015 and 2017, the intervention helped GPs identify more youth with anxiety ( $p=0.002$ for interaction), but not depression. The increase was most significant among the patients' regular GPs, less when patients met other GPs and least among external substitute physicians. The frequency of diagnoses with unspecified symptoms decreased in the intervention arm.

Conclusion Shared care with mental health professionals located in GP office contributed to increased detection of youth with anxiety symptoms. The increase was most prominent when the primary care physician was the patient's regular GP. GPs need to pay greater attention to detecting anxiety in youth and embrace shared care models, thereby contributing to reduced mental health disorders in this age group.

Trial registration number NCT03624829; Results.

\section{INTRODUCTION}

The WHO describes serious youth mental disorders-the most common being anxiety
Strengths and limitations of this study

- A strength of the study of diagnostics of young people with mental disorders was the clusterrandomised design comparing general practitioners (GPS) with and without close collaboration with a psychologist and a psychiatrist.

- The study also examines the importance of the physicians' relationships with the youth (regular GP, other GP, substitute physician).

- Diagnostics is part of the GPs' routine activity, thus providing relatively objective data for the GPs' activity.

- The presence of many patients with non-Norwegian ethnic backgrounds and lower socioeconomic conditions in the three boroughs located in the northeast of Oslo rendered the sample less representative of the country as a whole.

- A limitation is the unknown accuracy of GPs' diagnostical assessments.

and depression ${ }^{1}{ }^{2}$-as one of the greatest health challenges of our time. ${ }^{2-5}$ Anxiety or depression commonly coexist in adolescents, ${ }^{67}$ which may result in poor health ${ }^{8}$ and impaired functioning in their family, community, school and work. $^{9-12}$ Suicide ranks high as a cause of death in this age group. ${ }^{13-15}$ The WHO report emphasises that most mental health issues are neither detected nor addressed, ${ }^{3}$ even though more than half of adults with mental disorders had their first symptomatic onset before age $14 .^{3}$ Early detection of mental health disorders can provide great benefits for both individual patients and society, ${ }^{16}{ }^{17}$ making early detection a vital clinical opportunity, especially for general practitioners (GPs), who are often the first point of contact for people with mental health disorders and see them at an early stage. ${ }^{18-20}$

GPs use their clinical experience and simple, practical approaches when seeing 
patients. ${ }^{20}{ }^{21}$ When GPs look for mental disorders in youth, they may focus on identifying youth with symptoms of depression. ${ }^{22}{ }^{23}$ Yet several studies show that depression can be challenging to detect in this age group, ${ }^{21}{ }^{22}$ partly because it is difficult to distinguish between normal mood changes and a depressive episode that may progress into a more serious mental disorder. ${ }^{24}$ The mental health problems of the majority of youth therefore remain undetected. ${ }^{21}$ Although depression is the most commonly reported psychiatric symptom or disorder in general practice, GPs report a lack of training as a major cause of under-detection. ${ }^{21} 2526$ To our knowledge, studies that explore the connection between the GPs' relationship (regular GP, other GP at same office, external substitute physician) to young patients and how it affects the diagnosis of their mental health problems are also lacking.

Youth report anxiety symptoms to a lesser extent than depressive symptoms, ${ }^{25} 27-30$ possibly because the search for symptoms of depression overshadows their other mental health problems. For this age group, mental health problems may also be hidden behind somatic symptoms. ${ }^{31}$

Shared mental healthcare is an interdisciplinary approach to assist individuals with mental health problems ${ }^{32}$ by improving collaboration and strengthening partnerships between mental health and primary care services. In one such programme in Hamilton, Canada, GPs (family physicians) and mental health providers have worked together for over 25 years to improve treatment. ${ }^{33}$ GPs are supported by mental health professionals in their offices and regular visits from a psychiatrist. ${ }^{334}$ An evaluation $^{35}$ demonstrated that GPs reported improvement of their skills, were more comfortable seeing patients with mental health challenges and recognised the benefit to their patients. ${ }^{36}$ Canada has 35000 GPs to the country's population of just under 38 million (population/GPs is 1086), and primary care is perceived as the foundation of Canada's healthcare system, including mental health. ${ }^{37}$

In Norway, the GP is also a cornerstone of the health services, ${ }^{38}$ with 5000 GPs for 5.2 million inhabitants (population/GPs is 1040) and 99\% of the population on a GP's list. ${ }^{39}$ Several studies have been conducted to find models for better collaboration between GPs and psychiatric specialists. ${ }^{41}$ The conditions for collaboration are similar in Canada and Norway, ${ }^{38}$ with GPs increasingly working in group practices, but it is more common to find other health professionals within the GP's office in Canada. Both patients and GPs in Norway would likely benefit from better collaboration with psychologists and psychiatrists from second-line and municipal health services. ${ }^{40}$

In this study, we investigated the outcomes of a Canadian model of shared mental healthcare adapted for the Norwegian health service. We wanted to assess whether shared care with mental health professionals located in GP offices would increase the detection of mental health disorders in patients aged 16-24. In addition, we wanted to explore if the type of consulting physician and age or gender showed any significant differences in the diagnoses and whether an increased diagnosis of mental health disorders was associated with a decreased use of a selection of unspecified symptom diagnoses among the participating GPs.

\section{METHOD}

This study is a cluster-randomised, controlled trial, ${ }^{39}$ that focuses on a sample of 16-24year-olds and was conducted in Oslo, Norway.

\section{Design}

Two GP offices were recruited from the boroughs of Grorud, Stovner and Alna, ${ }^{39}$ with a large proportion of immigrants and low socioeconomic inhabitants. There were 3-8 GP offices in each borough, and the two GP offices were recruited by extending invitations to medium-sized GP offices. For each borough, one GP office was randomised to the intervention group and the other to the control group. The control group continued to practice as usual. Randomisation was done by a statistician not involved in the project and using randomisation procedure in Excel. The randomisation was done after all six GP offices had signed an agreement for participation and randomisation.

\section{Intervention}

Based on the Norwegian model of GPs in a publicly regulated system, the main emphasis was on counselling and advice to the GPs at the offices. A clinical psychologist and a psychiatrist from the local community mental health centre were co-located and collaborated with GPs in their offices for 18 months. The psychologist was present for 2.5 days a week and the psychiatrist for 2 hours a week. ${ }^{39}$ They provided general guidance related to specific patients, participated in selected consultations with patients and gave short-term treatment to selected patients.

\section{Data collection}

We extracted data on patients aged 16-24 from the existing electronic patient records at all six GP offices. ${ }^{39}$ Data were extracted for 12 months before the 2015 intervention and retrospectively in 2017 for the last 12 months of the 18 months with collaborative care (from approximately 6 months after the start of the collaborative care to exclude data from the starting phase of collaborative care). There were no exclusion criteria. ${ }^{39}$

All participating offices had a team of regular GPs, each having their own patient lists. For each visit, a patient could contact their regular GP; another substitute GP or an external substitute physician, who was at the GP offices for a brief period.

Each patient was assigned a unique ID number across both data collection periods. In addition, for each consultation, we determined the patient's regular GP and which physician the patient met. 


\section{Sample}

\section{Outcomes}

The outcomes of the study were the number of patients and consultations with a diagnosis of anxiety (A-diagnoses), depression (D-diagnoses), psychological diagnoses (P-diagnoses, defined as a diagnosis of anxiety and/or depression) and unexplained symptom diagnoses (S-diagnoses). Two experienced GPs (authors ORH and SG) identified a substantial number of S-diagnoses, such as tiredness, headache, abdominal pain and unexplained musculoskeletal disorder symptoms. Only patients with exclusively S-diagnoses were classified as S-diagnosis patients. The diagnostic classification was based on the GP's International Classification of Primary Care 2 (ICPC-2) - the classification system used in Norway's primary healthcare service. There were no exclusion criteria.

\section{Statistical analyses}

Data from the two periods were described by frequencies and percentages for each outcome (D-diagnoses, A-diagnoses, P-diagnoses and S-diagnoses) for all included patients, stratified by intervention and control arm. Data exhibited a hierarchical structure with three levels; consultations within patients were nested within consulting physician, nested within GP office. The intraclass correlation coefficient quantifying the proportion of total variance in the outcome accounted for by clustering on a certain level was calculated for each level. Akaike's Information Criterion (AIC) and Bayes Information Criterion (BIC), where the smaller value means a better model, were applied to assess the hierarchical structure to be included as random effects into the regression models.

A generalised linear mixed model with fixed effects for the time, study arm and interaction between time and study arm was estimated to assess intervention effect on outcome variables. A significant interaction would imply differences between study arms regarding the change in specific diagnoses from 2015 to 2017. The model included random effects for consultation within the patient, nested within the patient's GP. The intervention versus control effect was negligible according to AIC/BIC and therefore not included. Analyses stratified by a consulting physician (regular GP, other GPs, external substitute physician) and by the patient's and physician's gender and age were performed by estimating the same model as above with additional fixed effects for stratification variable and all necessary interactions (variable by time, variable by study arm and variable by time by study arm). Patients contacting a GP during only one period were compared with patients contacting a GP during both periods by a generalised linear mixed model with fixed effects for patient characteristics and the same random effects as the model above.

Due to the presence of interaction terms, results of the generalised linear mixed models were tabulated as regression coefficients and SEs and illustrated graphically as ORs and 95\% CIs. All tests were two-sided. Results with $\mathrm{p}$ values below 0.05 were considered statistically significant. Analyses were performed in SPSS V. 26 and STATA V.14.

\section{Ethics}

This article answered a part of research question 4 in the protocol published on Clinical Trials by analysing changes in the ICPC-2 codes as a secondary outcome associated with shared care in the cluster-randomised controlled trial.

The National Committee for Medical and Health Research Ethics (NEM) determined that the study fulfilled the necessary legal criteria to extract structured register data from the GP offices without giving the patients information or asking for written consent. These three legal criteria were that it is difficult to obtain consent, that the research is of significant interest to society, and that the planned procedures safeguard the welfare and integrity of the participants. In addition, NEM considered it difficult and inappropriate to provide written information to a total of more than 30000 patients registered at the six GP offices for each of the two rounds of data extraction.

\section{Patient and public involvement}

A service user expert by experience in the National Centre for Service User Competence in Mental Health was advisor for the project in planning the study. The local sections of the user organisation Mental Health Norway were invited to be involved in the implementation of the three collaborative care teams, but only one group was able to recruit a service user who participated. A representative for the Service User Council of Akershus University Hospital has participated in the project group during the process of data analyses, interpretation and publication of the results. As mentioned above, NEM approved that the study fulfilled the necessary legal criteria to extract structured register data from the GP offices without giving the large number of registered GP patients information or asking for written consent. Due to this, dissemination of the results may not be given directly to individual patients but only through service user organisations.

\section{RESULTS}

Information from patients aged 16-24 was collected from 6038 consultations with GPs in 2015 and 2017. Some patients consulted the GP more than once. The mean age was 19.5 ( $\mathrm{SD}=2.7) ; 2367(52.7 \%)$ of the 4490 unique patients were women. Thus, each age group was reasonably equally represented. GPs accounted for $20 \%$ of the variability, and GP offices accounted for $4 \%$ of the variability in P-diagnoses. Table 1 presents the number of patients and the occurrence of diagnoses before and after intervention in both study arms.

There were no differences in the occurrence of A-diagnoses, D-diagnoses, P-diagnoses and S-diagnoses between those who participated only in 2015 , only in 2017 , or in both periods (data not presented). 
Table 1 Distribution of patients, consultations, average numbers of consultations, consultations per patient and diagnoses $\mathrm{n}$ (\%) from 12-month period before the intervention (2015) and 12-month period during the intervention (2017)

\begin{tabular}{|c|c|c|c|c|}
\hline & \multirow[b]{2}{*}{ Period } & \multicolumn{2}{|c|}{ Number in intervention and control arm } & \multirow[b]{2}{*}{ Total (n) } \\
\hline & & Intervention & Control & \\
\hline Patients & 2015 & 1003 & 1911 & 2914 \\
\hline \multirow[t]{2}{*}{ Consultations } & 2015 & 4453 & 8653 & 13106 \\
\hline & 2017 & 5283 & 7893 & 13176 \\
\hline Average number of consultations per patient & 2017 & 4.7 & 3.9 & 4.2 \\
\hline \multicolumn{5}{|l|}{ Number of consultations per patient $(2015 / 2017)$} \\
\hline 1 & & $241 / 225$ & $399 / 523$ & $640 / 748$ \\
\hline 2 & & $171 / 195$ & $352 / 397$ & $523 / 592$ \\
\hline 3 & & $155 / 151$ & $286 / 299$ & $441 / 450$ \\
\hline \multirow[t]{2}{*}{ Anxiety (A-diagnoses) } & 2015 & $29(0.65)$ & $156(1.80)$ & 185 \\
\hline & 2017 & $79(1.50)$ & $80(1.01)$ & 159 \\
\hline \multirow[t]{2}{*}{ Depression and/or anxiety (P-diagnoses) } & 2015 & $105(2.36)$ & $363(4.20)$ & 468 \\
\hline & 2017 & $211(3.99)$ & $218(2.76)$ & 429 \\
\hline \multirow[t]{2}{*}{ Unexplained symptoms (S-diagnoses) } & 2015 & $1008(22.46)$ & $1755(20.28)$ & 2763 \\
\hline & 2017 & $1189(22.51)$ & $1685(21.35)$ & 2874 \\
\hline
\end{tabular}

According to the generalised linear mixed model, there was a significant difference between the intervention and control arms in the change in A-diagnoses between 2015 and 2017 ( $p=0.002$ for interaction). Post hoc analyses showed that odds for A-diagnoses increased 2.3 times in the intervention arm $(p=0.022)$ and were $40 \%$ lower in the control arm $(p=0.028)$. No differences were found in D-diagnoses, P-diagnoses or S-diagnoses (see table 2 and figure 1).

According to stratified analyses for A-diagnoses, two significant interactions were identified. First, increasing GP's age was significantly associated with lower odds for A-diagnoses in the intervention arm in 2015 ( $\mathrm{OR}=0.9$, 95\% CI (0.9 to 1.0), $\mathrm{p}=0.040)$ and higher odds in 2017 ( $\mathrm{OR}=1.1,95 \% \mathrm{CI}$ (1.0 to 1.2$), \mathrm{p}=0.006)$; there was no association in the control arm. Overall, arms differed significantly regarding this association ( $\mathrm{p}=0.009$ for interaction). Second, the odds for A-diagnoses were significantly higher in 2017 than in 2015 among GPs in the intervention arm $(\mathrm{OR}=3.5,95 \%$ CI (1.5 to 8.2), $\mathrm{p}=0.004)$, with no changes among other GPs or external substitutes and no changes in the control arm. The difference between intervention and control arms in change among GPs was significant $(\mathrm{OR}=5.6,95 \%$ CI (2.1 to 15.2$), \mathrm{p}=0.001)$. Post hoc analyses revealed the odds for A-diagnoses were significantly lower for other GPs versus substitute GPs in the control arm in $2015(\mathrm{OR}=0.2,95 \% \mathrm{CI}(0.1$ to 0.4$), \mathrm{p}<0.001)$ and $2017(\mathrm{OR}=0.3,95 \%$ CI $(0.1$ to 0.8$), \mathrm{p}<0.001)$.
Post hoc analyses revealed the odds of receiving A-diagnoses in 2017 were significantly higher than in 2015 for men in the intervention arm $(\mathrm{OR}=4.1,95 \% \mathrm{CI}(1.4$ to 11.8$), \mathrm{p}=0.010)$. Differences between study arms in the change of A-diagnoses were significant among men $(\mathrm{OR}=5.4,95 \%$ CI $(1.4$ to 20.8$), \mathrm{p}=0.014)$, but not women. Patient age was positively and significantly associated with higher odds of receiving A-diagnoses in the intervention arm in $2017(\mathrm{OR}=1.3,95 \%$ CI (1.0 to 1.6$)$, $\mathrm{p}=0.047$ ).

Stratified analyses of D-diagnoses, P-diagnoses and S-diagnoses showed no overall difference between strata for differences between arms before and after intervention (non-significant interactions).

Although there were no overall differences between study arms, the odds for P-diagnoses were significantly lower in the control arm when the consulting doctor is 'other GP at the same office' compared with 'regular GP' in $2015(\mathrm{OR}=0.3,95 \% \mathrm{CI}(0.2$ to 0.5$), \mathrm{p}<0.001)$ and $2017(\mathrm{OR}=0.2,95 \% \mathrm{CI}(0.1$ to 0.4$), \mathrm{p}<0.001)$. In addition, the odds for P-diagnoses were significantly lower in the control arm when the consulting physician was 'external substitute' versus 'regular GP' in 2017 (OR=0.3, 95\% CI (0.2 to 0.6$), \mathrm{p}=0.001)$, but not 2015 .

Physician age was positively associated with higher odds for S-diagnoses in the intervention arm in 2017 (OR=1.02, $95 \%$ CI (1.00 to 1.03$), \mathrm{p}=0.011)$. However, among regular GPs, the odds of S-diagnoses were significantly lower in 
Table 2 Results of a generalised linear mixed model for the difference between study arms in the change in the occurrence of A-diagnoses, D-diagnoses, P-diagnoses and S-diagnoses. The model includes random effects for consultation within patient, nested within patient's GP

\begin{tabular}{lcc}
\hline Parameter & Regr.coeff. (SE) & P value \\
\hline A-diagnoses & & \\
\hline Intercept & $-8.91(0.53)$ & $<0.001$ \\
\hline Period (2015-ref.) & $-0.52(0.24)$ & 0.028 \\
\hline Study arm (Control-ref.) & $-0.99(0.52)$ & 0.057 \\
\hline PeriodxStudy arm & $1.34(0.43)$ & 0.002 \\
\hline D-diagnoses & & \\
\hline Intercept & $-8.20(0.44)$ & $<0.001$ \\
\hline Period & $-0.01(0.17)$ & 0.943 \\
\hline Intervention & $0.09(0.49)$ & 0.854 \\
\hline PeriodxIntervention centre & $-0.44(0.35)$ & 0.212 \\
\hline P-diagnoses & & \\
\hline Intercept & $-7.21(0.37)$ & $<0.001$ \\
\hline Period & $-0.17(0.15)$ & 0.231 \\
\hline Intervention centre & $-0.28(0.46)$ & 0.552 \\
\hline PeriodxIntervention centre & $0.21(0.28)$ & 0.455 \\
\hline S-diagnoses & & \\
\hline Intercept & $-1.75(0.08)$ & $<0.001$ \\
\hline Period & $0.03(0.06)$ & 0.598 \\
\hline Intervention centre & $0.06(0.12)$ & 0.634 \\
\hline PeriodxIntervention centre & $-0.12(0.10)$ & 0.198 \\
\hline IPenat & & \\
\hline
\end{tabular}

GP, general practitioner.

2017 than in $2015(\mathrm{OR}=0.8,95 \%$ CI $(0.7$ to 1.0$), \mathrm{p}=0.046)$ in the intervention arm.

\section{DISCUSSION}

GPs increased their rate of anxiety diagnosis in youth after collaboration with mental health professionals located in their offices. The increase was most prominent when the patients met with their regular GP, lower for substitute GPs and lowest for external substitute physicians. Shared care did not result in more diagnoses of depression. After the intervention ended, the frequency of diagnoses with unspecified symptoms decreased in the intervention arm.

\section{Strength and weaknesses of the study}

One strength of this study is its cluster-randomised control. Making a diagnosis is a routine part of the GPs' work, and thus provides relatively objective data for the GPs' activity. No significant differences in any diagnosis pattern were found for GPs participating in either versus both 2015 and 2017, indicating homogeneous sample. A limitation is the unknown accuracy of GP's diagnostical assessments, although another Norwegian study found that the quality of GP's diagnostic assessments was reasonably good. ${ }^{42}$ Many patients with non-Norwegian ethnic backgrounds and lower socioeconomic conditions rendered the sample less representative of the country but better represented the country's most vulnerable youth groups. Randomisation resulted in a control group approximately two times as large as the intervention group due to variation in borough size, patient numbers and GP numbers in each GP office. These factors may have influenced the results. From 2015 to 2017, there was a slight but non-significant decrease in the number diagnosed with depression in the control group. An explanation may be changes in society and the local environment. Despite the decrease in the control group, the decrease in the number diagnosed with depression is significant in the intervention group.

\section{Comparison with existing studies}

Consistent with the findings of other studies, ${ }^{9} 1643$ anxiety often co-occurs with depression ${ }^{67}$ and anxiety is probably easier to recognise, even when the young person presents with only unexplained symptoms. ${ }^{31}$ It would be helpful to know if improved attention and detection of anxiety symptoms also lead to detection and treatment of youth with depression-a highly treatable condition-as detecting depression in youth can be a major challenge. ${ }^{29}{ }^{30}$ The challenge may be related to a lack of awareness of the significance of symptoms of depression among patients and their parents, along with feelings of shame often triggered by these symptoms. ${ }^{44}$ Our findings support this suggestion that patient age and maturity were positively associated with increased odds of psychological diagnoses in 2015 and 2017, regardless of any intervention. We also found that although the number of anxiety diagnoses increased after the intervention, the number of symptom diagnoses decreased. Previous baseline research demonstrated a positive association between the number of symptoms and mental diagnoses, ${ }^{39}$ perhaps because the shared care expertise increases the diagnosis of underlying mental disorders.

The shared care model may appear to have a greater impact on practice in Canada than in Norway. Even in Canada, a mental-health team does not automatically improve detection rates, but it does improve GPs' comfort in working with individuals with mental health problems. ${ }^{36}$ In Norway, the intervention was adapted to local conditions and the health services organisation. ${ }^{39}$ Collaboration primarily consisted of informal discussions between mental health professionals and the GPs, who remained responsible for the ongoing care of their patients. In the Canadian model, however, the mental health team (psychiatrist and mental health counsellor, but especially the counsellor/psychologist) may see people with mental health problems on an ongoing basis for treatment or support and monitoring, thereby sharing some of the care that would otherwise have been provided by the GP. ${ }^{34} 36$

\section{Implications for research and practice}

Youth with serious mental disorders present a significant challenge for our healthcare systems. For young people, 

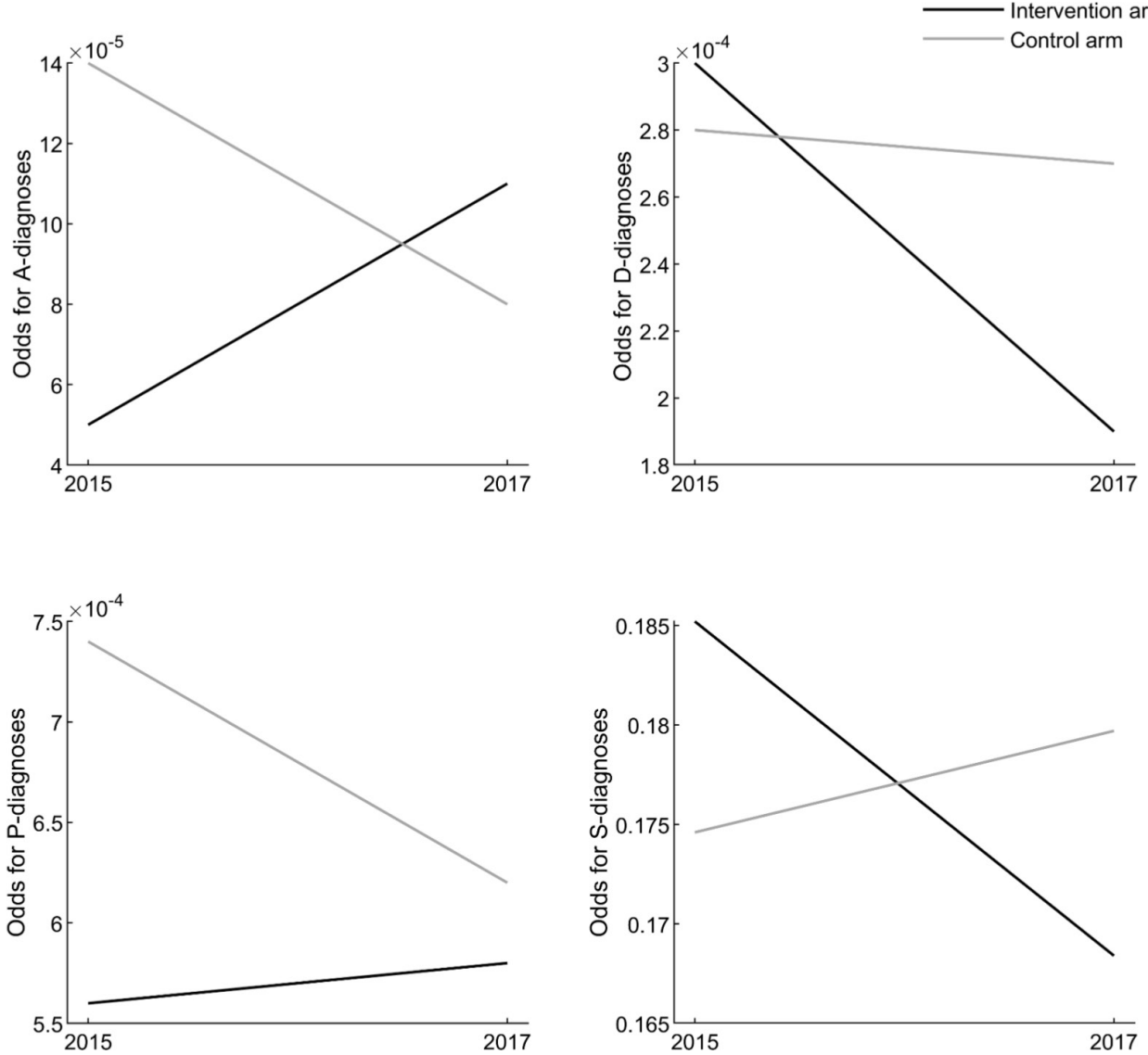

Figure 1 The results of generalised linear mixed model for the difference between study arms in the change in occurrence of A-diagnoses, D-diagnoses, P-diagnoses and S-diagnoses from 2015 to 2017.

GPs are often the first contact with the health service. Unfortunately, the majority of severe mental disorders among youth go undetected and therefore receive no assistance. Greater focus on anxiety and the way it can present, and the broader introduction of a shared care model with a psychologist or psychiatrist may contribute to the identification of more youth with mental health challenges in primary care. In addition, researchers need to examine other potential benefits of shared care for the early identification, including training in the use of screening tools, prevention and treatment of mental disorders in youth, and examine ways of increasing the detection of depression.

AcknowledgmentsWe thank the service user expert by experience in the National Centre for Service User Competence in Mental Health who participated with advice in planning the study and the local member of Mental Health Norway who participated when the study was conducted. We also thank the representative for the Service User Council of Akershus University Hospital who participated in the project group during the process of data analyses, interpretation and publication of the results.

Contributors $\mathrm{ORH}$ is responsible for the overall content. ORH, JŠB, SG and TR had full access to all of the data in the study and take responsibility for the integrity of the data and the accuracy of the data analysis. MPD and ORH recruited the GP offices and did the physical extraction of electronic medical data from the different GP office centres. ORH, SG, MPD, KH-B, NK and TR contributed to the plan and design of the study. ORH, SG and JŠB performed the data analyses. ORH drafted the manuscript and was together with TR in charge of the study planning. All authors have revised the manuscript critically for important intellectual content, and have given final approval of the version to be published and agreement to be accountable for all aspects of the work in ensuring that questions related to the accuracy or integrity of any part of the work are appropriately investigated and resolved.

Funding The authors have not declared a specific grant for this research from any funding agency in the public, commercial or not-for-profit sectors.

Competing interests None

Patient consent for publication Not applicable.

Ethics approval statement This cluster-randomised study was registered in ClinicalTrials.gov, Results (NCT03624829) and obtained the necessary approvals from The Regional Committee for Medical and Health Research Ethics South-East (REC, reg. no. 2014/435), The National Committee for Medical and Health Research Ethics (NEM, reg. no. 2014/160) and the Data Protection Officer at Akershus University Hospital (reg. no. 2013-138).

Provenance and peer review Not commissioned; externally peer reviewed.

Data availability statement Data are available upon reasonable request. The dataset analysed in the current study is available from the principal investigator (TR) on reasonable request.

Open access This is an open access article distributed in accordance with the Creative Commons Attribution Non Commercial (CC BY-NC 4.0) license, which permits others to distribute, remix, adapt, build upon this work non-commercially, and license their derivative works on different terms, provided the original work is properly cited, appropriate credit is given, any changes made indicated, and the use is non-commercial. See: http://creativecommons.org/licenses/by-nc/4.0/.

ORCID iD

Ole Rikard Haavet http://orcid.org/0000-0002-6847-8727

\section{REFERENCES}

1 Bandelow B, Michaelis S. Epidemiology of anxiety disorders in the 21st century. Dialogues Clin Neurosci 2015;17:327-35. 
2 Patel V, Flisher AJ, Hetrick S, et al. Mental health of young people: a global public-health challenge. Lancet 2007;369:1302-13.

3 WHO. Adolescent mental health 2019.

4 Blum RW, Bastos FIPM, Kabiru CW, et al. Adolescent health in the 21st century. Lancet 2012;379:1567-8.

5 Miranda-Mendizabal A, Castellví P, Parés-Badell O, et al. Gender differences in suicidal behavior in adolescents and young adults: systematic review and meta-analysis of longitudinal studies. Int $J$ Public Health 2019;64:265-83.

6 Brodbeck J, Abbott RA, Goodyer IM, et al. General and specific components of depression and anxiety in an adolescent population. BMC Psychiatry 2011:11:191.

7 Queen AH, Barlow DH, Ehrenreich-May J. The trajectories of adolescent anxiety and depressive symptoms over the course of a transdiagnostic treatment. J Anxiety Disord 2014;28:511-21.

8 Khairandish Z, Jamali L, Haghbin S. Role of anxiety and depression in adolescents with chest pain referred to a cardiology clinic. Cardiol Young 2017;27:125-30.

9 Bhatia MS, Goyal A. Anxiety disorders in children and adolescents: need for early detection. J Postgrad Med 2018;64:75-6.

10 Sörberg Wallin A, Koupil I, Gustafsson J-E, et al. Academic performance, externalizing disorders and depression: 26,000 adolescents followed into adulthood. Soc Psychiatry Psychiatr Epidemiol 2019;54:977-86.

11 Homlong L, Rosvold EO, Haavet OR. Can use of healthcare services among 15-16-year-olds predict an increased level of high school dropout? A longitudinal community study. BMJ Open 2013;3:e003125

12 Wille $\mathrm{N}$, Bettge $\mathrm{S}$, Wittchen $\mathrm{H}-\mathrm{U}$, et al. How impaired are children and adolescents by mental health problems? results of the BELLA study. Eur Child Adolesc Psychiatry 2008;17 Suppl 1:42-51.

13 Verger P, Brabis P-A, Kovess V, et al. Determinants of early identification of suicidal ideation in patients treated with antidepressants or anxiolytics in general practice: a multilevel analysis. J Affect Disord 2007;99:253-7.

14 Hill RM, Castellanos D, Pettit JW. Suicide-Related behaviors and anxiety in children and adolescents: a review. Clin Psychol Rev 2011;31:1133-44.

15 Mento C, Silvestri MC, Muscatello MRA, et al. Psychological pain and risk of suicide in adolescence. Int J Adolesc Med Health 2020. doi:10.1515/ijamh-2019-0270. [Epub ahead of print: 17 Apr 2020].

16 Kessler D, Bennewith O, Lewis G, et al. Detection of depression and anxiety in primary care: follow up study. BMJ 2002;325:1016-7.

17 Kessler RC, Angermeyer M, Anthony JC, et al. Lifetime prevalence and age-of-onset distributions of mental disorders in the world Health organization's world mental health survey initiative. World Psychiatry 2007;6:168-76.

18 Montgomery J, Hendry J, Wilson JA, et al. Pragmatic detection of anxiety and depression in a prospective cohort of voice outpatient clinic attenders. Clin Otolaryngol 2016:41:2-7.

19 Lundstrøm LH. Improving the care of adolescents in general practice. Br J Gen Pract 2014;64:216-7.

20 O'Brien D, Harvey K, Howse J, et al. Barriers to managing child and adolescent mental health problems: a systematic review of primary care practitioners' perceptions. Br J Gen Pract 2016;66:e693-707.

21 Carey M, Yoong SL, Grady A, et al. Unassisted detection of depression by GPs: who is most likely to be misclassified? Fam Pract 2015:32:282-7.

22 Hinrichs S, Owens M, Dunn V, et al. General practitioner experience and perception of child and adolescent mental health services (CAMHS) care pathways: a multimethod research study. BMJ Open 2012;2. doi:10.1136/bmjopen-2012-001573. [Epub ahead of print: 12 11 2012].

23 Gledhill J, Kramer T, lliffe S, et al. Training general practitioners in the identification and management of adolescent depression within the consultation: a feasibility study. J Adolesc 2003;26:245-50.
24 Leahy D, Schaffalitzky E, Saunders J, et al. Role of the general practitioner in providing early intervention for youth mental health: a mixed methods investigation. Early Interv Psychiatry 2018;12:202-16.

25 Kramer T, lliffe S, Bye A, et al. Testing the feasibility of therapeutic identification of depression in young people in British general practice. J Adolesc Health 2013;52:539-45.

26 Birrane J, Swan D, Aherne D, et al. Development and evaluation of an educational intervention in youth mental health for primary care practitioners. Ir J Psychol Med 2015;32:137-46.

27 Stockings E, Degenhardt L, Lee YY, et al. Symptom screening scales for detecting major depressive disorder in children and adolescents: a systematic review and meta-analysis of reliability, validity and diagnostic utility. J Affect Disord 2015;174:447-63.

28 Wasserman C, Postuvan V, Herta D, et al. Interactions between youth and mental health professionals: the youth aware of mental health (yam) program experience. PLoS One 2018;13:e0191843.

29 Bertha EA, Balázs J. Subthreshold depression in adolescence: a systematic review. Eur Child Adolesc Psychiatry 2013;22:589-603.

30 Wesselhoeft R, Sørensen MJ, Heiervang ER, et al. Subthreshold depression in children and adolescents - a systematic review. $J$ Affect Disord 2013;151:7-22.

31 van Boven K, Lucassen P, van Ravesteijn $\mathrm{H}$, et al. Do unexplained symptoms predict anxiety or depression? ten-year data from a practice-based research network. Br J Gen Pract 2011;61:e316-25.

32 Kates N, Arroll B, Currie E, et al. Improving collaboration between primary care and mental health services. World J Biol Psychiatry 2019;20:748-65.

33 Kates N, Craven M, Bishop J. Shared mental health care in Canada. Can J Psychiatry 1997;42. suppl 12 pp.

34 Kates N, Craven M. Shared mental health care. Canadian psychiatric association and College of family physicians of Canada joint Working group. Can Fam Physician 1999;45:2143-4.

35 Kates N, Craven M. Collaborative Working group of the College of family physicians of Canada CPA. shared mental health care. Update from the Collaborative Working Group of the College of Family Physicians of Canada and the Canadian Psychiatric Association. Can Fam Physician 2002;48:936.

36 Kates N, McPherson-Doe C, George L. Integrating mental health services within primary care settings: the Hamilton family health team. J Ambul Care Manage 2011;34:174-82.

37 Kates N, Hutchison B, O'Brien P, et al. Framework for advancing improvement in primary care. Healthc Pap 2012;12:8-21.

38 Mulvale G, Wilson F, Jones S, et al. Integrating mental health peer support in clinical settings: lessons from Canada and Norway. Healthc Manage Forum 2019;32:68-72.

39 Piiksi Dahli M, Brekke M, Ruud T, et al. Prevalence and distribution of psychological diagnoses and related frequency of consultations in Norwegian urban general practice. Scand J Prim Health Care 2020:1-8.

40 Seierstad TG, Brekke M, Toftemo I, et al. Gps' and child and adolescent psychiatry specialists' experiences of joint consultations in the GP's office: a qualitative study. BMC Res Notes 2017;10:458.

41 Grimholt TK, Haavet OR, Jacobsen D, et al. Perceived competence and attitudes towards patients with suicidal behaviour: a survey of general practitioners, psychiatrists and internists. BMC Health Serv Res 2014;14:208.

42 Sporaland GL, Mouland G, Bratland B, et al. General practitioners' use of ICPC diagnoses and their correspondence with patient record notes. Tidsskr Nor Laegeforen 2019;139. doi:10.4045/ tidsskr.18.0440. [Epub ahead of print: 22 Oct 2019].

43 Lazaratou H, Anagnostopoulos DC, Vlassopoulos M, et al. Predictors and characteristics of anxiety among adolescent students: a Greek sample. Psychiatriki 2013;24:27-36.

44 Salaheddin K, Mason B. Identifying barriers to mental health helpseeking among young adults in the UK: a cross-sectional survey. $\mathrm{Br}$ J Gen Pract 2016;66:e686-92. 